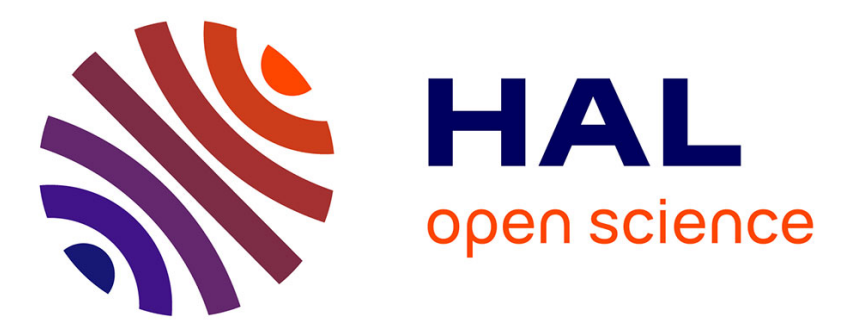

\title{
Postpartum psychological distress associated with anal incontinence in the EDEN mother-child cohort
}

Xavier Fritel, Bertrand Gachon, Saurel-Cubizolles Mj

\section{To cite this version:}

Xavier Fritel, Bertrand Gachon, Saurel-Cubizolles Mj. Postpartum psychological distress associated with anal incontinence in the EDEN mother-child cohort: Postpartum psychological distress and anal incontinence. BJOG: An International Journal of Obstetrics and Gynaecology, 2019, Epub ahead of print. 10.1111/1471-0528.16075 . inserm-02434984

\section{HAL Id: inserm-02434984 https://www.hal.inserm.fr/inserm-02434984}

Submitted on 10 Jan 2020

HAL is a multi-disciplinary open access archive for the deposit and dissemination of scientific research documents, whether they are published or not. The documents may come from teaching and research institutions in France or abroad, or from public or private research centers.
L'archive ouverte pluridisciplinaire HAL, est destinée au dépôt et à la diffusion de documents scientifiques de niveau recherche, publiés ou non, émanant des établissements d'enseignement et de recherche français ou étrangers, des laboratoires publics ou privés. 


\section{$1 \quad$ Title}

2 Postpartum psychological distress associated with anal incontinence in the EDEN mother-

3 child cohort.

\section{Authors}

$5 \quad$ Fritel X, 1

6 Gachon B, 1

7 Saurel-Cubizolles MJ, 2

8 and the EDEN Mother-Child Cohort Study Group

9 EDEN Mother-Child Cohort Study Group: Annesi-Maesano I, Bernard JY, Botton J,

10 Charles MA, Dargent-Molina P, de Lauzon-Guillain B, Ducimetière P, de Agostini M,

11 Foliguet B, Forhan A, Fritel X, Germa A, Goua V, Hankard R, Heude B, Kaminski M,

12 Larroque $\mathrm{B} \dagger$, Lelong N, Lepeule J, Magnin $\mathrm{G} \dagger$, Marchand L, Nabet C, Pierre F, Slama R,

13 Saurel-Cubizolles MJ, Schweitzer M, Thiebaugeorges O. († deceased)

\section{Institutions}

15 1. University Hospital of Poitiers, Gynaecology and Obstetrics Department, F-86000

16 Poitiers, France.

17 2. Université de Paris, Epidemiology and Statistics Research Centre/CRESS-EPOPé,

18 INSERM, INRA, F-75004 Paris, France

19 Correspondence

20 Prof. Xavier FRITEL

21 Service de Gyn-Obs, CHU de Poitiers, rue de la Milétrie, F-86000 Poitiers, France

22 Phone +33 549443 360. xavier.fritel@inserm.fr

\section{Running title}

24 Postpartum psychological distress and anal incontinence 
26 Objective: To estimate the prevalence of flatus-only and faecal incontinence, to describe 27 their risk factors, and to analyse the association between anal incontinence and 28 psychological distress over the first 1 year postpartum.

29 Design: Cohort study from pregnancy to 12 months postpartum

30 Setting: Two university hospital maternity wards in France

31 Population: 2002 pregnant women were recruited between 2003 and 2006. Data on anal incontinence was available for the 1632 women who comprise the sample for analysis.

33 Methods: Women were enrolled during pregnancy. A postal questionnaire was sent at 4 34 and 12 months postpartum.

35 Main Outcome Measures: Anal (flatus-only and faecal) incontinence was assessed at 4 36 months postpartum. Mental health was assessed at 4 and 12 months postpartum by the 37 Edinburgh Postpartum Depression Scale (EPDS) and use of antidepressant drugs as well as by self-rated mental health.

39 Results: At 4 months postpartum, the prevalence for flatus-only incontinence was $4014.4 \%$ and for faecal incontinence 1.7\%; multivariate analysis, restricted to women 41 reporting no anal incontinence before the index pregnancy, showed that continuing 42 breastfeeding at 4 months was related to a higher risk of de novo postpartum anal 43 incontinence $(\mathrm{OR}=2.23)$. Women who reported anal incontinence at 4 months were more 44 frequently depressed (EPDS $\geq 10$ or antidepressant use) at 12 months postpartum: $36.0 \%$ 45 of those with faecal incontinence were depressed, $23.3 \%$ of those with flatus-only 46 incontinence, and only $14.8 \%$ of the continent women.

47 Conclusion: Postnatal faecal incontinence was rare but associated with poorer maternal mental health. Postnatal screening should be encouraged, and psychological support 49 offered. 
50 Funding: Fondation pour la Recherche Médicale, INSERM, Ministère de la Recherche,

51 Université Paris Sud, Agence Nationale de la Recherche, Institut de Recherche en Santé

52 Publique, Agence Française pour la Surveillance et la Sécurité de l'Environnement et du

53 Travail, Santé Publique France, Direction Générale de la Santé, Association de Langue

54 Française pour l'Etude du Diabète et du Métabolisme, Mutuelle générale de l'Education

55 Nationale, Nestlé

56 Keywords: postpartum, anal incontinence, depression, cohort study

57 Tweetable abstract: Postnatal faecal incontinence was associated with depression; postnatal

58 screening should be encouraged and psychological support offered. 
61 In the year after childbirth, one in eight women develops a depressive illness; this

62 distressing episode for new mothers can have dramatic consequences on the baby's health. ${ }^{1}$

63 The main risk factors for postpartum depression are history of depression, low partner 64 support, anxiety, and stressful life events. ${ }^{1,2,3}$

65 Anal or faecal incontinence is a disability that has repercussions on health-related quality 66 of life and mood. ${ }^{4}$ Depression is two to five times more frequent in people with faecal 67 incontinence. ${ }^{5-7}$ The main risk factors for anal incontinence are ageing, diarrhoea, anorectal 68 surgery, and childbirth. The risk of developing faecal incontinence after giving birth is 69 between 1 and $10 \%$, and 6 to $45 \%$ of women have symptoms of flatus incontinence. ${ }^{8-14}$ 70 Major obstetrical risk factors are anal sphincter tears and instrumental delivery. ${ }^{8,9,15}$

71 The nature and direction of the association between faecal incontinence and depression 72 remain controversial. ${ }^{16,17}$ On the one hand, faecal incontinence may induce or worsen 73 depression; on the other hand, depression may impair sphincter control or worsen 74 perception of incontinence. A woman suffering from postnatal depression might be more 75 likely to report symptoms about flatus incontinence than women without depression; and a woman suffering from anal incontinence may consider that her quality of life has 77 deteriorated due to childbirth and thus develop postnatal depression, which can impair the 78 mother-child relationship. We found few postpartum studies on the subject. ${ }^{18-21}$ A Google 79 search brought up many internet groups discussing this topic and suggests that woman 80 giving birth are substantially concerned about it.

81 Our main aim was to analyse the association between anal incontinence and depressive symptoms during the first postpartum year, based on data from a two-centre cohort study. 
$\underline{\text { Population }}$

86 The EDEN mother-child cohort (Etude sur les Déterminants pré et postnatals précoces du 87 développement psychomoteur et de la santé de l'ENfant) invited pregnant women attending a prenatal visit in the Obstetrics and Gynaecology departments of the Nancy and Poitiers University Hospitals (France) before 24 weeks of gestation to participate.

90 Enrolment started in February 2003 in Poitiers and in September 2003 in Nancy and lasted

9127 months in each centre. Exclusion criteria were twin pregnancies, known diabetes before pregnancy, inability to speak and read French, and intention to move away from the region. Among women who met these inclusion criteria, 55\% agreed to participate (969 in Poitiers and 1033 in Nancy). The study was approved by the Ethics Committee of the KremlinBicêtre Hospital. Written consent was obtained from the mother at enrolment. More

96 information about the EDEN cohort can be found on the web (http://eden.vjf.inserm.fr/)

97 and in the article describing the cohort profile. ${ }^{22}$

Demographic and social details, including mother's age, educational level, household income, smoking status, and weight, were obtained in a face-to-face interview at 24 to 28

100 weeks of gestation, at the same time that midwife research assistants measured the

101 mother's height. Data on previous pregnancies, deliveries, birth weight of previous

102 children, and weight gain in the index pregnancy were extracted from obstetric records.

103 Marital status and relationship quality (measured from questions included in the postal

104 questionnaire completed at 1 year) were summarised by an indicator in 3 classes: women

105 living with the baby's father with a good relationship, women living with the baby's father

106 with problems, and women not living with the baby's father (see Table S1). 
108 At 4 months postpartum, the following questions were asked in a postal questionnaire:

109 "During the last month, have you experienced involuntary leakage of gas or stools?

110 yes/no", "If yes, involuntary leakage of gas? Involuntary leakage of liquid stools?

111 Involuntary leakage of solid stools?" These three questions were answered on a 4-point

112 scale: never/less than once a week/at least once a week/every day. ${ }^{23}$ From the answers to

113 these questions, women were classified into three groups, those with no anal incontinence,

114 with flatus-only incontinence, and with faecal (stool) incontinence. Data about anal

115 continence before the index pregnancy were obtained at 4 months postpartum.

\section{$116 \quad$ Mental health assessment}

117 The women's mental health was measured with several indicators. First, we used the CESD

118 questionnaire (completed at the end of the second-trimester) to evaluate the mood state of

119 pregnant women and considered women with a CESD score below 16 as "not depressed". ${ }^{24}$

120 Second, the postnatal questionnaires, completed at 4 and 12 months after delivery,

121 included questions about perceived physical health ("During the last month, how have you

122 been feeling physically? very well/rather well/rather poorly/very poorly") and perceived

123 mental health ("During the last month, how have you been feeling from a mental point of

124 view? very well/rather well/rather poorly/very poorly"). Third, the postnatal questionnaires

125 also included the Edinburgh Postnatal Depression Scale (EPDS) ${ }^{25}$ women with a score of

12610 or above were considered to have depressive symptoms and defined as depressed.

127 Fourth, those questionnaires also asked about the postnatal use of antidepressant drugs

128 during the preceding month ("yes/no"). Lastly, in the days after the birth, women

129 responded to the question: "Have you ever been hospitalised in a psychiatry ward, before 130 this pregnancy began? no/yes". 


\section{$131 \quad \underline{\text { Analysis }}$}

132 We estimated the prevalence of flatus-only incontinence and faecal incontinence at 4

133 months postpartum. The prevalence was analysed according to social, demographic, and

134 medical factors. Adjusted odds ratios of de novo flatus-only incontinence and faecal

135 incontinence (among women reporting that they did not have anal incontinence before the

136 pregnancy) were calculated by polychotomous logistic regression to take into account

137 simultaneously each factor and incontinence severity (no incontinence, flatus only, faecal 138 incontinence).

139 The relations between anal incontinence and mental health at 4 months and 12 months

140 postpartum were studied by logistic regressions to adjust for the following factors:

141 women's age, psychiatric hospitalisation before the index pregnancy, relationship, previous

142 delivery of infant weighing $4000 \mathrm{~g}$ or more, perineal tear at index delivery, breastfeeding,

143 hospitalisation of the baby in the first year, and medical centre. These factors were related

144 to the exposure (anal incontinence) or to poor mental health, or to both. As complementary

145 sensitivity analyses, these logistic regression models were run on a sample restricted to the

146 women not classified as depressed during the second-trimester of pregnancy. Each logistic

147 regression was adjusted for the medical centre. The statistical analysis was performed with

148 SAS version 9.4 software.

149 Patients were not involved in the development of the EDEN cohort. No core outcome sets

150 were used because no core outcome set for this topic has yet been developed. 


\section{Results}

153 Questionnaires at 4 months postpartum were returned by 1668 of the 2002 women 154 included at baseline, a response rate of $83.3 \%$. Comparisons with the non-respondents 155 showed that respondents were more likely to be 30 years or older (50.7 vs. $38.0 \%$ ), 156 married, smokers, and to have higher household incomes. They also had vaginal deliveries 157 more often ( 87.8 vs. $64.7 \%$ ). The response rate did not differ according to centre, parity, or

158 BMI. Data on anal incontinence was available for 1632 women, who make up the main 159 sample analysed.

$160 \quad$ Prevalence of anal incontinence at 4 months postpartum

161 The prevalence of anal incontinence was $16.1 \%(n=263,95 \%$ confidence interval: $14.3-$ $16217.9 \%$ ) at 4 months postpartum. Prevalence of flatus-only incontinence was $14.4 \%$ (235, $16312.7-16.1 \%)$ and of faecal incontinence $1.7 \%(28,1.1-2.3 \%)$. Among women who did not 164 have anal incontinence before the index pregnancy $(n=1587), 14.0 \%$ (223) reported de 165 novo anal incontinence, $12.5 \%$ (199) de novo flatus-only incontinence, and $1.5 \%$ (24) de 166 novo faecal incontinence.

167 The prevalence of postnatal anal incontinence was higher among women aged 30 years or 168 older, who ever had an instrumental vaginal delivery, ever had a baby weighing $4000 \mathrm{~g}$ or 169 more, or was still breastfeeding (Table 1). The prevalence of flatus-only incontinence or 170 faecal incontinence did not differ significantly among women with caesarean compared 171 with spontaneous vaginal deliveries.

172 Logistic regression - restricted to women reporting that they did not have anal

173 incontinence before the index pregnancy - retained only one significant risk factor 174 associated with de novo anal incontinence: continued breastfeeding (Table 2). The 175 proportion of multiparous women ( $\geq 3$ deliveries) among the 45 women reporting anal 
176 incontinence before their index pregnancy was significantly higher $(31.1 \%)$ than among

177 those continent before this pregnancy $(n=1584,17.9 \%)$, as was the proportion of women

178 who had had a baby weighing $4000 \mathrm{~g}$ or more than (respectively $20.0 \%$ and $8.6 \%$ ).

\section{Anal incontinence and mental health}

180 At 4 months postpartum, women with anal incontinence reported that their physical and

181 mental health was "rather poor" or "very poor" more frequently than the others (Table 3).

182 The percentage of depressed women was especially high among women with faecal 183 incontinence $(50.0 \%)$ but also higher in women with flatus incontinence $(26.6 \%)$ than in 184 continent women (17.2\%).

185 Women who had reported anal incontinence at 4 months reported poor mental health more 186 often at 12 months; they were also more frequently depressed and used antidepressant 187 drugs much more often at 12 months (Table 3). For instance, $6.4 \%$ of women with anal 188 incontinence were using antidepressant drugs 1 year after the birth compared to $2.6 \%$ of 189 women without anal incontinence. The percentage of depressed women (defined by the

190 EPDS score) was $22.1 \%$ among women with anal incontinence compared to $13.5 \%$ among

191 continent women (Table 3). The analysis excluding women depressed during their second-

192 trimester of pregnancy found similar odds (Table S2).

193 In the overall population, the odds ratios of antidepressant drug use were significantly

194 higher for women with flatus incontinence as well as for those with faecal incontinence.

195 The odds ratio of depression was significantly higher among women with flatus-only or

196 faecal incontinence (Table 4). This association between mental health 1 year after delivery

197 and anal incontinence was similar in the sample restricted to women without anal

198 incontinence before the index pregnancy and not depressed during the second-trimester of 199 pregnancy (Table 4). 


\section{Discussion}

202 Main findings

203 In our population with a follow-up to 1 year postpartum, faecal incontinence at 4 months 204 postpartum was rare but was followed by a significant risk of depressive symptoms and use 205 of antidepressant drugs 8 months later.

\section{Strengths and limitations}

207 Our study has several weaknesses; variables such as prenatal anal incontinence, length of 208 the active second phase of labour, and the existence of an episiotomy or perineal tear were 209 only collected at the 4-month postpartum questionnaire; the infrequency of faecal 210 incontinence (1.7\% at 4 months postpartum in our sample) limits the power of the

211 statistical analysis; we have no information on intestinal transit. The strengths of this study

212 are its large sample; which came from a general population of recent mothers, in an 213 organised regular cohort that continued past one year, the high response rates, and the 214 quality of the data on mental health.

\section{Interpretation}

216 The prevalence of flatus-only incontinence or faecal incontinence in our population, 14.4

217 and $1.7 \%$, respectively, is consistent with that reported by other studies between 3 and 6 218 months postpartum, with figures ranging from $6.3 \%$ to $45.3 \%$ for flatus incontinence and 219 between 0.7 and $9.6 \%$ for faecal incontinence. ${ }^{9-14}$

220 In the general population older than 50 years, depression appears to be 2 to 5 times more 221 frequent in people with faecal incontinence. ${ }^{5-7}$ Data are sparse about the possible association between anal incontinence and depression in the postnatal period. In a crosssectional study of 1331 women at 6 months postpartum, bowel problems were associated

224 with postpartum depression (EPDS $\geq 13$; OR 1.9, CI95\% 1.3-2.9). ${ }^{18}$ A retrospective study 
of 294 women referred after delivery (mean 24 days) reported that anal incontinence was

226 not associated with postpartum depression (EPDS $\geq 10) .{ }^{19}$ In another small study of 284

227 primiparous women interviewed 10 months after childbirth, severe dysphoria was

228 associated with dyspareunia $(2.5 ; 1.4-4.6)$ but not with anal incontinence $(0.7 ; 0.4-1.2){ }^{20}$

229 In the large enquiry by MacArthur of 4214 women, persistent faecal incontinence at 6

230 years postpartum was associated with poor perceived health and a higher Hospital Anxiety

231 and Depression score (mean score 7.6 versus 5.4). ${ }^{21}$

232 We used longitudinal data from the second-trimester of pregnancy and then at 4 and 12

233 months postpartum to explore the association between anal incontinence and depressive

234 symptoms. Our results suggest that anal incontinence is associated with poorer perceived

235 physical and mental health at 4 months postpartum and that this association persists at 12

236 months for mental but no longer for physical health. The observation of anal incontinence

237 at 4 months postpartum could thus alert clinicians about the risk of depression persisting up

238 to 12 months after delivery and enable early screening and management of this postnatal

239 depression.

240 Our results can be interpreted in favour of a causal link between postnatal anal

241 incontinence and depression: ${ }^{26}$ i) Gradient: all measurements of mental health (EPDS

242 questionnaire, perceived mental health, and antidepressant use) were consistent with a

243 gradient linked to the intensity of exposure (stronger with faecal incontinence than with

244 flatus); ii) Temporality: women with de novo faecal incontinence (related to childbirth) at

2454 months postpartum were at a higher risk of depression at one year; excluding women

246 depressed during the second trimester of pregnancy or reporting anal incontinence before

247 pregnancy produced similar odds; iii) Analogy: we also found an association between

248 postnatal urinary incontinence and depression in the EDEN cohort. ${ }^{27}$ 
249 Faecal incontinence and depressive disorders are both somewhat taboo subjects that

250 women do not often report spontaneously at postnatal consultations. ${ }^{28}$ Fewer than $20 \%$ of

251 women are questioned about anal continence during this visit. ${ }^{28}$ Because of the serious

252 harmful consequences of postpartum depression on the health of both women and their

253 babies, it appears important to increase clinicians' awareness, especially in primary care, of

254 the importance of screening for anal incontinence and depression at the postnatal

255 consultation and to offer psychological support in women with incontinence or depressive

256 symptoms. ${ }^{16,29}$ The RCOG recommend that women who have undergone an obstetric anal

257 sphincter injury or have anal incontinence should be referred to gynaecologists with a

258 specific interest in pelvic floor trauma. ${ }^{30}$

259 Conclusions

260 In clinical practice, our results should encourage each physician to look for signs of

261 postnatal depression related to anal incontinence. From the public health perspective, they

262 show how these two sensitive issues of women's health during their child-bearing years can

263 be intertwined, and they require further research for a better understanding of their

264 associations as well as for the most effective and empathetic management possible. 
267 The authors thank the members of the EDEN mother-child cohort study group, Jo Ann

268 Cahn for editing, and Laetitia Marchand-Martin for her useful advice in statistical analysis.

\section{Disclosure of interest}

270 We have no direct or indirect commercial financial incentive associated with publishing

271 the article.

\section{Contribution to authorship}

$273 \mathrm{XF}$ and MJSC contributed to the conception, design, analysis, interpretation of data and

274 article writing. BG contributed to analysis, interpretation of data and article writing. Each

275 author had access to the data analysis, participated in revising the manuscript and approved

276 the final submitted version.

\section{Details of Ethics Approval}

278 The CCPPRB (Comité de Consultation pour la Protection des Personnes se Prêtant à la

279 Recherche Biomédicale) of Kremlin-Bicêtre University Hospital approved EDEN cohort

280 (December $12^{\text {th }}, 2002$, reference number 02-70). The data files were registered with the

281 French Data Authority (CNIL, reference 902267).

\section{Funding}

283 We acknowledge all funding sources for the EDEN study: FRM (Fondation pour la

284 Recherche Médicale), INSERM, Ministère de la Recherche, Université Paris Sud (XI),

285 ANR (Agence Nationale de la Recherche), IRESP (Institut de Recherche en Santé

286 Publique), AFSSET (Agence Française pour la Surveillance et la Sécurité de

287 l'Environnement et du Travail), Santé Publique France (Institut National Pour 1'Education 
288 et la Santé, Institut National de Veille Sanitaire), DGS (Direction Générale de la Santé),

289 ALFEDIAM (Association de Langue Française pour l'Etude du Diabète et du

290 Métabolisme), MGEN (Mutuelle générale de l’Education Nationale), Nestlé.

291 
1 Wisner KL, Parry BL, Piontek CM. Postpartum depression. New Engl J Med 2002;347:194-9.

2 Pearlstein T, Howard M, Salisbury A, Zlotnick C. Postpartum depression. Am J Obstet Gynecol 2009;200:357-64.

3 Gaillard A, Le Strat Y, Mandelbrot L, Keita H, Dubertret C. Predictors of postpartum depression: prospective study of 264 women followed during pregnancy and postpartum. Psychiatry Res 2014;215:341-6.

4 Philip B, Miner JR. Economic and personal impact of fecal and urinary incontinence. Gastroenterology 2004;126:S8-13.

5 Edwards NI, Jones D. The prevalence of fecal incontinence in older people living at home. Age Ageing 2001;30:503-7.

6 Andy UU, Vaughan CP, Burgio KL, Alli FM, Goode PS, Markland AD. Shared Risk Factors for Constipation, Fecal Incontinence, and Combined Symptoms in Older U.S. Adults. J Am Geriatr Soc 2016;64:e183-8.

7 Fritel X, Ringa V, Varnoux N, Zins M, Bréart G. Mode of Delivery and Fecal Incontinence at Midlife: A Study of 2,640 Women in the GAZEL Cohort. Obstet Gynecol 2007;110:31-8.

8 MacArthur C, Bick DE, Keighley MR. Fecal incontinence after childbirth. BJOG 1997;104:46-50.

9 Hatem M, Pasquier JC, Fraser W, Lepire E. Factors associated with postpartum urinary/anal incontinence in primiparous women in Quebec. J Obstet Gynaecol Can 2007;29:232-9.

10 MacArthur C, Glazener CMA, Wilson PD, Herbison GP, Gee H, Lang GD et al. Obstetric practice and faecal incontinence three months after delivery. BJOG 2001;108:678-83.

11 Groutz A, Fait G, Lessing JB, David MP, Wolman I, Jaffa A, et al. Incidence and obstetric risk factors of postpartum anal incontinence. Scand J Gastroenterol 1999;34:315-8.

12 van Brummen $\mathrm{HJ}$, Bruinse $\mathrm{HW}$, van de Pol G, Heintz AP, van der Vaart $\mathrm{CH}$. Defecatory symptoms during and after the first pregnancy: prevalences and associated factors. Int Urogynecol J Pelvic Floor Dysfunct 2006;17:224-30.

13 Chaliha C, Sultan AH, Bland JM, Monga AK, Stanton SL. Anal function: effect of pregnancy and delivery. Am J Obstet Gynecol 2001;185:427-32.

14 Faltin DL, Sangali MR, Roche B, Floris L, Boulvain M, Weil A. Does a second delivery increase the risk of anal incontinence? BJOG 2001;108:684-8.

15 Fritel X, Gachon B, Desseauve D, Thubert T. Incontinence anale et lésions obstétricales du sphincter anal, épidémiologie et prévention [Anal incontinence and obstetrical anal sphincter injuries, epidemiology and prevention]. Gynecol Obstet Fertil Senol 2018;46:419-26.

16 Bailey N, Pares D. Faecal incontinence and depression: cause or effect? Colorectal Dis 2010;12: 397-8. 
17 Vasudev K, Gupta AK. Incontinence and mood disorder: is there an association? BMJ Case Rep 2010. doi: 10.1136/bcr.07.2009.2118

18 Brown S, Lumley J. Physical health problems after childbirth and maternal depression at six to seven months postpartum. BJOG 2000;107:1194-1201.

19 Swenson CW, DePorre JA, Haefner JK, Berger MB, Fenner DE. Postpartum depression screening and pelvic floor symptoms among women referred to a specialty postpartum perineal clinic. Am J Obstet Gynecol 2018;218:335.e1-6.

20 Lal M, Pattison HM, Allan TF, Callender R. Postcesarean pelvic floor dysfunction contributes to undisclosed psychosocial morbidity. J Reprod Med 2009;54:53-60.

21 MacArthur C, Glazener C, Lanashire R, Herbison P, Wilson D, Grant A. Faecal incontinence and mode of first and subsequent delivery: a six-year longitudinal study. BJOG 2005;112:1075-82.

22 Heude B, Forhan A, Slama R, Douhaud L, Bedel S, Saurel-Cubizolles MJ, et al. Cohort Profile: The EDEN mother-child cohort on the prenatal and early postnatal determinants of child health and development. Int J Epidemiol 2016;45:353-63.

23 Pescatori M, Anastasio G, Bottini C, Mentasti A. New grading and scoring for anal incontinence, evaluation of 335 patients. Dis Colon Rectum 1992;35:482-7.

24 van der Waerden J, Bernard JY, De Agostini M, Saurel-Cubizolles MJ, Peyre H, Heude $B$ et al. Persistent maternal depressive symptoms trajectories influence children's IQ: The EDEN mother-child cohort. Depress Anxiety 2017;34:105-17.

25 Cox JL, Holden JM, Sagovsky R. Detection of postnatal depression: Development of the 10-item Edinburgh Postnatal Depression Scale. Br J Psychiatry 1987;150:782-6.

26 Hill A. The environment and disease: association or causation? Proc R Soc Med. 1965;58:295-300.

27 Fritel X, Tsegan YE, Pierre F, Saurel-Cubizolles MJ, EDEN Mother-Child Cohort Study Group. Association of postpartum depressive symptoms and urinary incontinence. A cohort study. Eur J Obstet Gynecol Biol Reprod 2016;198:62-7.

28 Brown S, Gartland D, Perlen S, McDonald E, MacArthur C. Consultation about urinary and faecal incontinence in the year after childbirth: a cohort study. BJOG 2015;122:954-962.

29 Fritel X. Should we systematically ask about postnatal incontinence? BJOG 2015;122:963.

30 Royal college of Gynaecologists and Obstetricians. The management of third-and fourth- degrees perineal tears. Green-top guidelines $N^{\circ} 29$. June 2015. Available: https://www.rcog.org.uk/globalassets/documents/guidelines/gtg-29.pdf 
Table 1. Women's characteristics and 4 months postpartum anal incontinence (no incontinence, flatus-only, or faecal incontinence) Fisher's exact test with Monte Carlo simulation.

\begin{tabular}{|c|c|c|c|c|c|}
\hline \multirow[b]{3}{*}{ Women's characteristics } & \multirow{3}{*}{$\begin{array}{l}N \\
1632\end{array}$} & \multicolumn{4}{|c|}{ Anal incontinence at 4 months postpartum } \\
\hline & & \multirow{2}{*}{$\begin{array}{l}\text { Faecal } \\
\%(n) \\
1.7(28)\end{array}$} & \multirow{2}{*}{$\begin{array}{l}\text { Flatus-only } \\
\%(n) \\
14.4(235)\end{array}$} & \multirow{2}{*}{$\begin{array}{l}\text { No } \\
\%(n) \\
83.9(1369)\end{array}$} & \multirow[b]{2}{*}{$P$} \\
\hline & & & & & \\
\hline younger than 30 & 802 & $1.1(9)$ & $12.1(97)$ & $86.8(696)$ & \multirow{2}{*}{0.004} \\
\hline 30 or older & 830 & $2.3(19)$ & $16.6(138)$ & $81.1(673)$ & \\
\hline Below high school diploma & 403 & $3.0(12)$ & $11.9(48)$ & $85.1(343)$ & \multirow{4}{*}{0.011} \\
\hline High-school diploma (baccalauréat) & 295 & $2.0(6)$ & $11.5(34)$ & $86.4(255)$ & \\
\hline University, 1st degree & 363 & $1.4(5)$ & $14.3(52)$ & $84.3(306)$ & \\
\hline University, more than 1st degree & 547 & $0.9(5)$ & $18.3(100)$ & $80.8(442)$ & \\
\hline $1500 €$ or less & 220 & $3.6(8)$ & $10.9(24)$ & $85.4(188)$ & \multirow{4}{*}{0.066} \\
\hline $1501-2300 €$ & 485 & $1.6(8)$ & $13.4(65)$ & $85.0(412)$ & \\
\hline Housenota montmiy incomes & 442 & $0.7(3)$ & $15.2(67)$ & $84.2(372)$ & \\
\hline more than $3000 €$ & 475 & $1.9(9)$ & $16.4(78)$ & $81.7(388)$ & \\
\hline \multirow{3}{*}{$\begin{array}{r}\text { living with baby's father, good relationship } \\
\text { living with baby's father, problems } \\
\text { not living with baby's father }\end{array}$} & 1097 & $1.4(15)$ & $12.9(142)$ & $85.7(940)$ & \multirow{3}{*}{0.005} \\
\hline & 457 & $2.4(11)$ & $19.0(87)$ & $78.6(359)$ & \\
\hline & 77 & $2.6(2)$ & $7.8(6)$ & $89.6(69)$ & \\
\hline \multirow{3}{*}{ Psychiatric hospitalisation before index pregnancy } & 1574 & $1.7(27)$ & $14.6(229)$ & $83.7(1318)$ & \multirow{2}{*}{0.785} \\
\hline & 50 & $2.0(1)$ & $10.0(5)$ & $88.0(44)$ & \\
\hline & 1381 & $1.4(19)$ & $15.0(207)$ & $85.8(1155)$ & \multirow[b]{2}{*}{0.034} \\
\hline Smoking during index pregnancy & 227 & $3.5(8)$ & $11.9(27)$ & $84.6(227)$ & \\
\hline \multirow{4}{*}{ Body mass index $\left(\mathrm{kg} / \mathrm{m}^{2}\right)$} & 130 & $2.3(3)$ & $13.8(18)$ & $83.8(109)$ & \multirow{4}{*}{0.972} \\
\hline & 1051 & $1.6(17)$ & $14.4(151)$ & $84.0(883)$ & \\
\hline & 282 & $1.8(5)$ & $15.6(44)$ & $82.6(233)$ & \\
\hline & 137 & $2.2(3)$ & $12.4(17)$ & $85.4(117)$ & \\
\hline Primipara: $1^{\text {st }}$ child & 735 & $1.2(9)$ & $12.6(93)$ & $86.1(633)$ & \multirow{3}{*}{0.023} \\
\hline Secondipara: $2^{\text {nd }}$ child & 596 & $1.5(9)$ & $14.9(89)$ & $83.6(498)$ & \\
\hline Multipara: $3^{\text {rd }}$ child or + & 298 & $3.4(10)$ & $17.8(53)$ & $78.9(235)$ & \\
\hline \multirow{3}{*}{ Mode of delivery (all deliveries) } & 198 & $2.0(4)$ & $9.6(19)$ & $88.4(175)$ & \multirow{3}{*}{0.006} \\
\hline & 1088 & $1.2(13)$ & $14.1(153)$ & $84.7(922)$ & \\
\hline & 346 & $3.2(11)$ & $18.2(63)$ & $78.6(272)$ & \\
\hline Any child with birth weight $\geq 4000$ g & 1480 & $1.7(25)$ & $13.5(200)$ & $84.8(1255)$ & 0005 \\
\hline Any cnila with Dirtn weignt $\geq 4000 \mathrm{~g}$ & 145 & $2.1(3)$ & $23.4(34)$ & $74.5(108)$ & 0.005 \\
\hline Weight gain in index pregnancy & 1441 & $1.9(27)$ & $14.3(206)$ & $83.8(1208)$ & 559 \\
\hline $20 \mathrm{~kg}$ or more & 159 & $0.6(1)$ & $14.5(23)$ & $84.9(135)$ & 0.539 \\
\hline episiotomy & 470 & $1.1(5)$ & $18.1(85)$ & $80.8(380)$ & \\
\hline Third-degree perineal tear & 90 & $2.2(2)$ & $13.3(12)$ & $84.4(76)$ & 0.074 \\
\hline vaginal with no tear or C-section & 1069 & $2.0(21)$ & $12.9(138)$ & $85.1(910)$ & \\
\hline Hospitalisation of the child in the 1 st vear & 1317 & $1.6(21)$ & $14.3(188)$ & $84.1(1108)$ & 0.692 \\
\hline mosplicallsation or the chila in the lst year & 315 & $2.2(7)$ & $14.9(47)$ & $82.9(315)$ & 0.092 \\
\hline no & 474 & $1.9(9)$ & $11.6(55)$ & $86.5(410)$ & \\
\hline breastfed $<4$ months & 637 & $1.3(8)$ & $12.6(80)$ & $86.2(549)$ & 0.002 \\
\hline still breastfeeding at 4 months & 521 & $2.1(11)$ & $19.2(100)$ & $78.7(410)$ & \\
\hline
\end{tabular}


Table 2. Risk factors for de novo anal incontinence at 4 months postpartum; multivariate polychotomous logistic regression with adjusted odds ratios $(N=1530)$, complete data missing for 57 women.

\begin{tabular}{|c|c|c|c|c|c|}
\hline \multirow[b]{3}{*}{$N=1530$} & \multicolumn{5}{|c|}{ Anal incontinence at 4 months postpartum } \\
\hline & \multicolumn{2}{|c|}{ Faecal } & \multicolumn{2}{|c|}{ Flatus-only } & \multirow{2}{*}{$\begin{array}{l}\text { No } \\
p\end{array}$} \\
\hline & $\mathrm{aOR}$ & $95 \% \mathrm{Cl}$ & $\mathrm{aOR}$ & $95 \% \mathrm{Cl}$ & \\
\hline \multicolumn{6}{|l|}{ Age (years) } \\
\hline$<30$ & 1 & & 1 & & $p=0.119$ \\
\hline$\geq 30$ & 2.07 & $0.80-5.36$ & 1.30 & $0.92-1.82$ & 1 \\
\hline \multicolumn{6}{|l|}{ Educational level } \\
\hline Below high school diploma & 1 & & 1 & & 1 \\
\hline High-school diploma (baccalauréat) & 0.54 & $0.16-1.80$ & 0.95 & $0.57-1.58$ & 1 \\
\hline University, 1st degree & 0.53 & $0.17-1.67$ & 0.90 & $0.55-1.48$ & 1 \\
\hline University, >1st degree & 0.20 & $0.05-0.78$ & 1.22 & $0.78-1.91$ & $p=0.214$ \\
\hline \multicolumn{6}{|l|}{ Relationship } \\
\hline living with baby's father, good relationship & 1 & & 1 & & $p=0.143$ \\
\hline living with baby's father, problems & 1.53 & $0.62-3.80$ & 1.48 & $1.06-2.05$ & 1 \\
\hline not living with baby's father & 1.64 & $0.34-7.94$ & 0.82 & $0.34-1.99$ & 1 \\
\hline \multicolumn{6}{|l|}{ Smoking during pregnancy } \\
\hline 4 & 1 & & 1 & & $p=0.210$ \\
\hline yes & 2.20 & $0.83-5.80$ & 0.84 & $0.50-1.39$ & 1 \\
\hline \multicolumn{6}{|l|}{ Parity } \\
\hline Primipara: $1^{\text {st }}$ child & 1 & & 1 & & $p=0.904$ \\
\hline Secondipara: $2^{\text {nd }}$ child & 0.98 & $0.34-2.85$ & 1.18 & $0.81-1.72$ & 1 \\
\hline Multipara: $3^{\text {rd }}$ child or + & 1.32 & $0.38-4.51$ & 1.15 & $0.70-1.88$ & 1 \\
\hline \multicolumn{6}{|l|}{ Mode of delivery (all deliveries) } \\
\hline caesarean only & 1 & & 1 & & $p=0.053$ \\
\hline vaginal spontaneous & 0.68 & $0.17-2.74$ & 1.50 & $0.82-2.77$ & 1 \\
\hline instrumental, at least one & 2.25 & $0.50-10.2$ & 1.90 & $0.96-3.77$ & 1 \\
\hline \multicolumn{6}{|l|}{ Any child with birth weight $\geq 4000 \mathrm{~g}$} \\
\hline ( & 1 & & 1 & & $p=0.090$ \\
\hline yes & 0.34 & $0.04-2.71$ & 1.59 & $0.98-2.56$ & 1 \\
\hline \multicolumn{6}{|l|}{ Perineal tear at index delivery } \\
\hline episiotomy & 0.74 & $0.23-2.32$ & 1.52 & $1.05-2.19$ & 1 \\
\hline third degree perineal tear & 1.23 & $0.25-6.02$ & 0.91 & $0.43-1.92$ & 1 \\
\hline vaginal with no tear or $\mathrm{C}$-section & 1 & & 1 & & $p=0.186$ \\
\hline \multicolumn{6}{|l|}{ Breastfeeding } \\
\hline no & 1 & & 1 & & $p=0.016$ \\
\hline breastfed $<4$ months & 1.02 & $0.33-3.13$ & 1.09 & $0.72-1.66$ & 1 \\
\hline still breastfeeding at 4 months & 2.23 & $0.75-6.60$ & 1.77 & $1.16-2.69$ & 1 \\
\hline
\end{tabular}

+ Medical centre: no significant contribution of the variable to the model, $p=0.888$ 
Table 3. Anal incontinence at 4 months postpartum and mental health at 4 and 12 months. Comparison between women with faecal incontinence, flatus-only incontinence, and no incontinence (Fisher's exact test with Monte Carlo simulation).

\begin{tabular}{|c|c|c|c|c|}
\hline \multirow[b]{2}{*}{ Postpartum mental health } & \multicolumn{3}{|c|}{ Anal incontinence at 4 months postpartum, \% (n/N) } & \multirow[b]{2}{*}{$p$} \\
\hline & $\begin{array}{l}\text { Faecal } \\
(\mathrm{N}=28)\end{array}$ & $\begin{array}{l}\text { Flatus-only } \\
(\mathrm{N}=235)\end{array}$ & $\begin{array}{c}\text { No } \\
(N=1369)\end{array}$ & \\
\hline \multicolumn{5}{|l|}{4 months postpartum } \\
\hline Perceived physical health "rather poor" or "very poor" & $10.7 \%(3 / 28)$ & $15.5 \%(36 / 232)$ & $7.8 \%(106 / 1364)$ & 0.002 \\
\hline Perceived mental health "rather poor" or "very poor" & $14.3 \%(4 / 28)$ & $13.4 \%(31 / 231)$ & $7.2 \%(98 / 1360)$ & 0.039 \\
\hline Depression (EPDS $\geq 10)$ & $50.0 \%(14 / 28)$ & $26.6 \%(62 / 233)$ & $17.2 \%(233 / 1353)$ & $<0.001$ \\
\hline Antidepressant drug use during last month & $3.6 \%(1 / 28)$ & $2.6 \%(6 / 230)$ & $1.9 \%(26 / 1340)$ & 0.765 \\
\hline Depression (EPDS $\geq 10$ ) or antidepressant drug use & $53.6 \%(15 / 28)$ & $27.2 \%(64 / 235)$ & $17.8 \%(244 / 1368)$ & $<0.001$ \\
\hline \multicolumn{5}{|l|}{12 months postpartum } \\
\hline Perceived physical health "rather poor" or "very poor" & $0.0 \%(0 / 25)$ & $12.9 \%(26 / 202)$ & $10.1 \%(122 / 1211)$ & 0.103 \\
\hline Perceived mental health "rather poor" or "very poor" & $12.0 \%(3 / 25)$ & $16.3 \%(33 / 202)$ & $8.5 \%(103 / 1209)$ & 0.004 \\
\hline Depression (EPDS $\geq 10$ ) & $28.0 \%(7 / 25)$ & $21.3 \%(42 / 197)$ & $13.5 \%(163 / 1206)$ & 0.004 \\
\hline Antidepressant drug use during last month & $13.6 \%(3 / 22)$ & $5.6 \%(11 / 198)$ & $2.6 \%(31 / 1185)$ & 0.007 \\
\hline Depression (EPDS $\geq 10$ ) or antidepressant drug use & $36.0 \%(9 / 25)$ & $23.3 \%(47 / 202)$ & $14.8 \%(181 / 1221)$ & $<0.001$ \\
\hline
\end{tabular}


Table 4. Anal incontinence at 4 months postpartum and mental health at 12 months postpartum. Logistic regression with odds ratios adjusted for women's age, psychiatric hospitalisation before index pregnancy, relationship, previous birth weight of $4000 \mathrm{~g}$ or more, perineal tear at index delivery, breastfeeding, hospitalisation of the baby in the $1^{\text {st }}$ year, and medical centre.

Mother's mental health 12 months after childbirth

\begin{tabular}{|c|c|c|c|c|c|c|}
\hline \multirow{2}{*}{$\begin{array}{l}\text { Anal incontinence at } \\
4 \text { months } \\
\text { postpartum }\end{array}$} & \multicolumn{2}{|c|}{ Depression (EPDS $\geq 10$ ) } & \multicolumn{2}{|c|}{ Antidepressant use } & \multicolumn{2}{|c|}{$\begin{array}{l}\text { Depression (EPDS } \geq 10 \text { ) o } \\
\text { antidepressant use }\end{array}$} \\
\hline & $\mathrm{aOR}$ & $95 \% \mathrm{Cl}$ & aOR & $95 \% \mathrm{Cl}$ & aOR & $95 \% \mathrm{Cl}$ \\
\hline \multicolumn{7}{|l|}{ In the overall population } \\
\hline & \multicolumn{2}{|c|}{$n / N=209 / 1415$} & \multicolumn{2}{|c|}{$n / N=45 / 1392$} & \multicolumn{2}{|c|}{$n / N=234 / 1435$} \\
\hline No & 1 & $P=0.019$ & 1 & $P=0.003$ & 1 & $P=0.002$ \\
\hline Flatus-only & 1.64 & $1.11-2.44$ & 2.70 & $1.28-5.68$ & 1.72 & $1.18-2.52$ \\
\hline Faecal & 2.11 & $0.84-5.31$ & 5.98 & $1.50-23.80$ & 2.87 & $1.21-6.81$ \\
\hline \multicolumn{7}{|c|}{ Among women reporting no anal incontinence before index pregnancy } \\
\hline & \multicolumn{2}{|c|}{$n / N=201 / 1377$} & \multicolumn{2}{|c|}{$\mathrm{n} / \mathrm{N}=42 / 1353$} & \multicolumn{2}{|c|}{$\mathrm{n} / \mathrm{N}=224 / 1395$} \\
\hline No & 1 & $p=0.036$ & 1 & $p=0.001$ & 1 & $p=0.003$ \\
\hline Flatus-only & 1.60 & $1.04-2.44$ & 2.93 & $1.31-6.58$ & 1.68 & $1.11-2.52$ \\
\hline Faecal & 2.25 & $0.83-6.08$ & 8.34 & $1.98-35.05$ & 3.24 & $1.28-8.20$ \\
\hline
\end{tabular}

Among women who were not depressed during $2^{\text {nd }}$ trimester of index pregnancy

\begin{tabular}{rrlrlrl} 
& \multicolumn{2}{c}{$\mathrm{n} / \mathrm{N}=103 / 986$} & $\mathrm{n} / \mathrm{N}=21 / 974$ & \multicolumn{2}{c}{$\mathrm{n} / \mathrm{N}=117 / 998$} \\
No & 1 & $p=0.045$ & 1 & $p=0.080$ & 1 & $p=0.008$ \\
Flatus-only & 1.66 & $0.96-2.88$ & 3.18 & $1.05-9.62$ & 1.78 & $1.06-3.01$ \\
Faecal & 3.31 & $0.96-11.47$ & 4.14 & $0.39-43.58$ & 4.34 & $1.33-14.13$
\end{tabular}

Among women reporting no anal incontinence before and not depressed during $2^{\text {nd }}$ trimester of index pregnancy

\begin{tabular}{rllllll} 
& \multicolumn{2}{c}{$\mathrm{n} / \mathrm{N}=98 / 961$} & $\mathrm{n} / \mathrm{N}=21 / 948$ & \multicolumn{2}{c}{$\mathrm{n} / \mathrm{N}=112 / 972$} \\
No & 1 & $p=0.071$ & 1 & $p=0.006$ & \multicolumn{1}{c}{1} & $p=0.007$ \\
Flatus-only & 1.51 & $0.83-2.75$ & 4.20 & $1.36-12.98$ & 1.71 & $0.97-3.00$ \\
Faecal & 4.16 & $1.00-17.27$ & 17.42 & $1.49-203.19$ & 6.23 & $1.65-23.59$ \\
\hline
\end{tabular}

